\title{
From a well-prepared teacher to an on-the-spot facilitator: a reflection on delivering an active learning course
}

DOI 10.1515/ijtr-2015-0005

received March 9, 2015; accepted June 8, 2015

\begin{abstract}
In this article, I describe my experience of preparing and delivering a brand new computing undergraduate course in a new university and in doing so, share how the special institutional push of the active learning pedagogy of the university changed the way I prepared and delivered the course, and ended up transforming my own view of teaching. I was faced with an unusual cohort of students who were already familiar with active learning styles in classes, were proactive, vocal, and argumentative, were not afraid of making mistakes and of challenging the authorities, were extremely articulate expressing themselves and who had worked in a project- and team-based setting throughout the programme. As such, a very different method of teaching needed to be in place, not for the purpose of improving the in-class engagement, but out of necessity. In the process of creating and running this course, I witnessed a major shift in the allocation of my time, efforts and other resources: from general to specific, from teaching to advising to observing, from elaborate preclass preparations to impromptu, in-class discussions, thus bringing all my design skills and experiences to the table.
\end{abstract}

Keywords: Active learning; student teams; interaction design studio; experience design; learning culture

*Corresponding author: Hyowon Lee, hlee@sutd.edu.sg

\section{Introduction}

Active learning has been very much discussed, studied and encouraged in primary and secondary educational settings as a desired model of instruction. However, the teaching pedagogy at third-level institutions has been largely in the form of traditional lecture halls, where a professor gives a formal lecture to 200 students for an hour or two. Apart from the resource issues that push back the student to instructor ratio in colleges/universities around the world, one of the reasons why this important and effective mode of instruction is not widely employed by third-level institutions may be the conception of adult students that learning is simply a matter of obtaining a useful set of information. Such an idea of learning as merely "knowledge transmission" is largely viewed now as being no longer adequate for today's environment, where knowledge itself is changing rapidly and access to information is becoming easier for everybody (Stewart, 2012). The process of learning and supporting effective and deep understanding, especially in the domains of science and engineering, tends to be left to the students' own devices rather than being pedagogically instrumented on the institutional level. In focusing on the mass production of a much-needed future workforce, the conventional mode of knowledge transfer through lectures is prevalent, even in top-ranked universities.

Only a sizable number of third-level institutes are offering an active learning mode of education in the fields of science and technology. For example, the Entertain Technology Centre (ETC) at the Carnegie Mellon University offers Master-level programmes based entirely on a series of team projects focusing on the applications of research and professional development (Goodman et al., 2013); Olin College ${ }^{1}$ in Massachusetts offers highly active learning programmes in a hands-on, practical, self-initiated and intimate environment for their engineering students,

1 http://www.olin.edu/ 
frequently topping some of the prestigious teaching review rankings; Maryland University continues to improve their innovative engineering design course that combines conventional lectures and project-based learning (Calabro et al., 2008). Evidence has also started to appear of traditional lecture courses being compared with active learning courses in terms of the students' overall performance in engineering undergraduate courses (e.g. Freeman et al., 2013; Linsey et al., 2009).

In particular, the majority of students in Asian universities today receive the conventional lecturing mode of classroom learning as a continuation of their primary, middle and high school experience in which one teacher, professor or instructor will lecture for 1-2 hours while they sit in the classroom. More recently, however, well-developed cities such as Hong Kong, Singapore and Seoul have started investing resources through various government-funded initiatives to transform this conventional and well-accepted mode of learning. These initiatives acknowledge the need for change, not only in the style of delivery, but in the more fundamental cultural and social perception of what education is (Stewart, 2012).

The university, in which the new course and its transformative aspects are described in this article, has enforced the understanding of this into a concrete and ambitious national project. The Singapore University of Technology and Design (SUTD), the $4^{\text {th }}$ nationally-funded university in Singapore, with its first batch of undergraduate student intake in 2012, is one of the first universities to unconditionally mandate the use of active learning across its entire curriculum. As a result, a newly-recruited faculty is creating active learning methodologies in virtually all courses undertaken in the university's curriculum. The university is already seeing innovative developments as the faculty develops materials that are suitable for such a model (Wood et al., 2012; Telenko et al., 2014) as well as various active learning-based courses in mathematics (Tsai et al., 2013), physics, humanities and social science. This development also includes more specialised disciplines such as software engineering, mechanical engineering and consumer product design.

It was in this institutional atmosphere of creating new courses in active learning in September 2014 that I developed and delivered a new active learning course on Human-Computer Interaction titled User-Interface Design and Implementation to 25 undergraduate students specialising in Information Systems Technology and Design. After three years of being immersed in active learning classes (over 20 courses by the end of three years), my students had already been expecting to continue in that mode of learning, which is unusual in the educational context of Asian countries as mentioned earlier. Because of this unusual cohort of students in the class, the design and delivery of the course had to be tailored for them in ways that I had not done or experienced before.

I, myself, went through a very typical conventional educational system, having gone through 12 years of fullday lecture-style classes and written exams in traditional primary, middle and high schools in Seoul, South Korea. My undergraduate education in Seoul also comprised 4 years of the traditional one-way mode of receiving lectures from professors and instructors. Thus, I had no concrete reference point for my knowledge of educational models other than the conventional method of lecturing until many years after I moved my position from sitting and learning to that of standing and teaching. I then started to seriously question the mode of learning and reflected on my own learning experience, motivation and drive.

Previously, I taught a course on Human-Computer Interaction (HCI) at Dublin City University, Ireland for ten years $(2001$ - 2011) in a very conventional, lecturing style mode of delivery with two design projects and a final exam for grading. In 2008, I attended studio discussions at CMU's Entertainment Technology Centre for one week (2008), and witnessed how their acclaimed project-based programme was conducted. I also attended an undergraduate course at MIT for the duration of a whole spring semester during my 1-year faculty development programme at MIT (2012 - 2013). In SUTD, I developed and delivered an advanced math course involving 10 faculty members and which was run in a highly active learning mode of delivery (Summer Semester, 2012). I delivered a fully project-based active learning design course that involved 15 faculty members from different disciplines with a huge coordination effort (Autumn Semester, 2013), followed by a more computer science-focused version of the course (Spring Semester, 2014). In developing and delivering the course concerned in this article, the considerations came from a series of reflections based on a combination of my own schooling with my early teaching experience, as well as my more recent observations of active learning courses, and eventually my experience in the delivery of courses that had strong active learning elements conditioned by the unusual pedagogical stance imposed by the new university.

This article begins by explaining the special characteristics of the student batch and how the course was deliberately and purposefully shaped that way by the university's overall pedagogical push. This will be followed by an explanation on how the process of designing and running the new course for this type of cohort students has altered my teaching philosophy. In addition, it will be 
shown how the extreme active learning focus of the university is not only transforming the culture of its classes and thus, the nature of its graduates, but is also transforming my own practice of developing, preparing, delivering and grading.

\section{Characterising the student teams}

As mentioned in the introduction, the university's entire curriculum was in the active learning mode and was design-focused ${ }^{2}$. The students had already completed a large number of team-based design projects before enrolling in the HCI course. For example, all the students in the second term of Year 1 had taken a multi-disciplinary course called "Introduction to Design." This course embodies the university's pedagogical stance in terms of design education, studio-style class format, active learning and a large multi-disciplinary team of instructors. A team of over 15 faculty members delivered the course as a joint and collaborative effort. The instructors' expertise spanned multiple disciplinary areas including information systems design, product engineering design, industrial design and architecture. Typically, a cohort class of 45 students was advised by 2-3 faculty members, each from a different disciplinary background and expertise. The students formed teams with 4-6 peers in each team, and were engaged in a semester-long design process involving brainstorming, user requirements and surveys, sketching, prototyping and evaluations, under the guidance of the multi-disciplinary team of instructors. In the preceding term (i.e. the very first term in the university) the students had attended foundational science and humanity courses rather than any specific technical disciplinary courses. Quite a few teams ended up using computing applications that required considerations on interaction design and end-user issues, typically featuring elements of computer science, industrial/ product/ systems design and user experience design. Having gone through this type of design project in their first year followed by a series

2 The focus on an active learning curriculum and being designfocused are related: design discipline often emphasises starting to act first before attempting to gain full understanding of the situation - only by acting and producing something first (e.g. a sketch, a drawing, a prototype, etc.) can a student gain some insights into the nature of what she/he is creating, thus helping to make it better in the next iteration. Not being afraid of making mistakes and taking action so that the most likely incomplete result of that action will inform the next iteration of action is an important basis for the design way of thinking. of more discipline-specific but likewise project-based courses in their second year, the students attending the course shared in this article in the third year were already very familiar with the technology design process in general and the approaches that are typically employed in such a process. This included dealing with teamwork situations, delivering the outcomes within the deadlines, working in a highly multi-disciplinary environment, and receiving advice from potentially conflicting points of view ${ }^{3}$, pitching and presenting their ideas and interim solutions effectively, communicating with other stakeholders and target end-users, as well as envisioning how some of the emerging technological concepts might be prototyped and applied in the real world. Most of the first year students did not as yet possess the in-depth technical expertise and skills required to implement products, services or applications at a professional level. Thus, most of the final prototypes and deliverables were not fully working systems or services but were more like proof-of-concept mock-ups that demonstrated their ideas. The purpose of this course was to expose the students to the full lifecycle of a technology design project before training them with the in-depth technical knowledge and skills. This nurtured a design-centric mind-set and gave the students a foretaste of working in a multi-disciplinary team environment. The students finally ended up in a better position to identify their specialty/strength/interest that they wanted to pursue, and they gained a wider perspective of where their individual skill set or knowledge fitted in with the whole spectrum of the design process. In their final year, the students were involved in a two-semester-long project, which was a technically rigorous and in-depth version of the first year design course.

All the other courses in the university are being similarly conducted in an active learning mode, where the students constantly form teams and engage in project-based and action-oriented activities throughout the course. By Year 3, the students will be extremely skilled in whiteboard brainstorming, able to argue convincingly, and to work in teams on short and long projects.

3 One of the typical complaints voiced by students of the programme is that the faculty instructors for their projects give very different kinds of advice on the same topic in question. This is how the students get exposed to different disciplinary points of view from Year 1 and learn to resolve such conflicts through systematic contacts with faculty instructors with different backgrounds. Having had only one teacher as their main point of contact for each subject throughout their primary and secondary education, most of the students require new attitudes of learning in order to deal with multiple instructors, each offering different points of view. 


\section{The new course I developed and taught}

The course shared in this article is an elective course offered to $3^{\text {rd }}$ year students in Information Systems Technology and Design. The aim of the course is to help students gain a deeper experience of the process that is specific to the design of user interaction and to teach the students how to evaluate user interfaces with various usability engineering techniques. The course concerned, User Interface Design and Implementation, was first offered in the autumn of 2014. It is an introductory course on HumanComputer Interaction, and was designed to be practical rather than theoretical. The course exposes students to a wide range of topics in HCI, including the methodological aspects (user-centred design, understanding users, establishing requirements, user testing, usability engineering and evaluation criteria, etc.), conceptual background (e.g. design principles, guidelines, heuristics, etc.), useful theoretical tools (e.g. Fitt's Law, click distance, colour theory, etc.) and other related "donor" disciplines such as graphic design, cognitive psychology and anthropology.

The physical classroom in which the students sit for this course is one of the university's cohort-based classrooms that have been specifically designed to effectively support the active learning delivery. All the tables, chairs and other furniture in the room are light-weight and "rollable," allowing easy formation of teams and re-arrangement of the room configuration during the class. Seven ceiling-mounted data projectors are available for projecting on all sides of the room, including the back wall, while 6-10 rollable whiteboards can be used to easily partition the groups and to mark the points of the collaborative brainstorming/sketching area. Photos of the class during some of their design studio sessions are shown in Figure 1.

The students applied the concepts and principles introduced in various mini discussions, activities and projects inserted throughout the class periods. The class hours included two 1.5-hour sessions and one 2-hour studio session each week, amounting to five classroom hours per week. ${ }^{4}$ For the first month-and-a-half of the course, the first two sessions of each week focused on introducing new concepts with examples, discussions and activities. The third session was dedicated to studio-type design

4 Five hours per week of classroom hours plus 2-3 more hours of office consultation time is typical of the courses in the university: active learning generally requires more time as it is necessary to incorporate the time not only to introduce/explain new concepts but also for the students to use and apply the concepts to various activities during the class. activities, where the student teams continued with their design projects, while my teaching assistant and I visited each team and engaged them in discussions and mentoring. For the remaining two months of the term, all the sessions were studio-type activities, focusing on the progress of the individual projects.
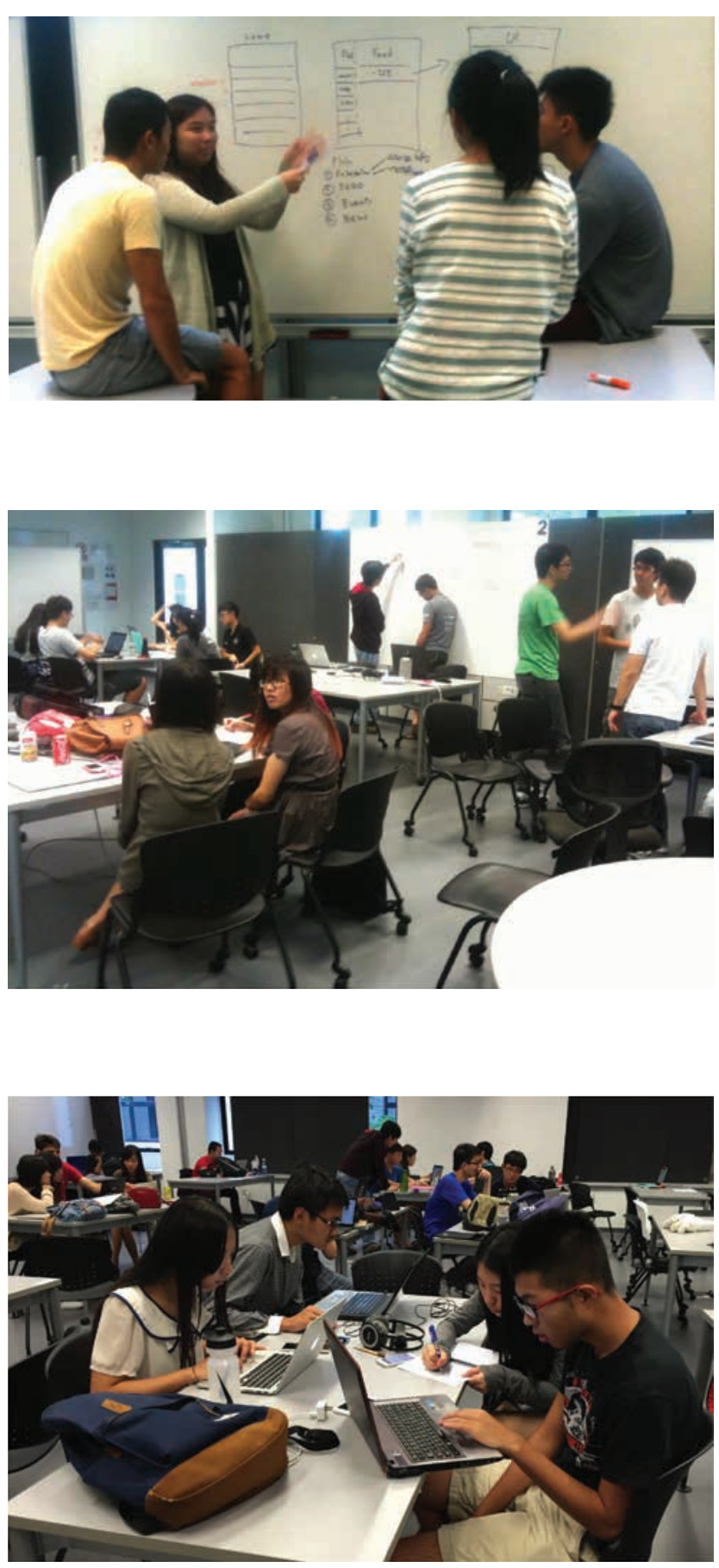

Figure 1: During the design studio session 


\section{Bringing design thinking and experience to the class}

In developing and delivering this course, I leveraged my experience in designing user-interfaces that take advantage of emerging technologies in a number of different interaction platforms (desktop, mobile, table-top, multitouch wall, in-home display and other embedded appliances) (Lee \& Smeaton, 2009). Having worked as a resident interaction designer and in-house usability expert in a large technology research centre for over a decade (Lee et al., 2013), I tried to bring my design experience and realworld example cases to the table throughout the course. For example, I had to include in the course materials many examples of designs from my recent projects, where specific problems arose due to various reasons: user-technology mismatch, dilemmas in having to come up with an initial sketch without fully understanding the problem, dealing with a large number of requirements in a single project, meeting deadlines in interaction design activities, prioritising among conflicting design guidelines, and dealing with conflicts with technical teams due to differing agenda and conflicting points of view, and so on.

One of the core skills and knowledge that this course has to offer is the designerly way of thinking and acting, where one starts working on solutions even without sufficient information at the start and takes advantage of the opportunistic and abductive nature of a design process (Cross, 2007; Lawson, 2005). This means that it is not enough to merely show my design examples or explain the process that led to those examples. It is difficult to extract the essence of my own knowledge-in-action, as much of it is not factual knowledge that can be objectively categorised but more of a right set of actions triggered by a particular mind-set and attitude through repeated cycles of thinking-sketching-reflecting. The studio-style sessions, which comprised $70 \%$ of the course, were exactly for that purpose. I wanted to demonstrate to the students and guide them on how to think and proceed given a particular situation that is typically lacking in clear understanding and identifiable requirements, which any engineering- or scientifically-inclined student may simply wait on without taking any action. In the context of an engineering school environment, it is difficult to implement an apprenticeship or a personalised mentorship as the main format of delivery and to map it to the student's learning outcomes in line with many other hard-core engineering courses.

As mentioned in the introduction, for ten years in Ireland I had taught an HCI course that was more focused on web design in a more traditional lecture mode of delivery. Then, in 2013, I spent one year in MIT as a visiting faculty member, during which I attended their undergraduate user-interface design course at the MIT Computer Science and Artificial Intelligence Lab, and monitored, observed and recorded its course delivery for a full spring semester. Since joining the SUTD, I have participated in the development and delivery of three active learning courses, all of which involved more than 10 faculty members, with weekly coordination meetings and inputs coming from a group of MIT as well as SUTD faculty members with extensive experience in running active learning classes. The new course I developed and delivered in SUTD was the accumulation and culmination of all these, with a significant additional context of a special student batch that was already familiar and comfortable with the multi-disciplinary, team-based active learning as enforced by the university. As $70 \%$ of the classes in this course are conducted as design studio sessions, bringing in my hands-on design experience connected well with the type of delivery required in the course, thus benefiting the students' learning.

\section{Experiencing the change}

Our students had mostly been educated in a typical Asian traditional secondary school system (including Singapore, Malaysia, South Korea, Myanmar and India) before starting off in this radically different active learning culture of our university curriculum. Thus, the most notable aspect of my experience of preparing and delivering this course was that I had to consider the special characteristics of my students, which I had never encountered before. This required some major re-thinking in the preparation, delivery, grading, and in the planning and running of the course in general. I already had a wealth of sample materials from my previous teaching as well as many of my own episodes of experiences in design. However, using these in the right way to maximise the students' learning of design thinking and practice, and meeting my students' expectations at the same time, proved to be tricky.

Developing an active learning course to encourage students to learn by doing things is one thing, but having a cohort of students who were already familiar with and were already expecting such a learning method, brought a new set of challenges, which pushed me to the limits in preparing the course. While some of the following reflections would generally be felt by anyone attempting to run an active learning class, I have highlighted here those 
aspects that transformed my view of teaching in terms of the preparation and delivery.

\subsection{From general knowledge to specific action}

I had no experience in delivering a course that had so few components on the actual teaching of general principles and basic concepts. I had always thought that the main duty of an instructor was to introduce new concepts and explain them in such a way as to be easily understood by the students, and that this constituted the bulk of the class hours. I found myself shifting from starting each class by giving a general summary or overview of the topic before moving into the examples and case studies, to starting with specific issues of the student teams and from there, relating them to the general summary or overview of the topic. Thus, I felt it was more appropriate to start each class by summarising the progress of each of the projects that the students were working on. From their specific requirements, needs and considerations, the lesson moved to introducing any relevant or significant principles, guidelines, heuristics or any other pieces of useful knowledge. The students showed a keen interest and paid attention when this seemingly reversed flow was executed in the class.

Due to the on-going, term-long project on which the entire grading of the course depended, the students' attention was firmly focused on their own projects. This proved to be an advantage for the instructor in terms of getting the attention of the students when explaining new concepts of the course, as long as the introduction and explanation kept relating back to their projects in some way. My preparation for the course each week then shifted from compiling general explanations to using project-specific issues as a starting point before leading them to the general principles and concepts that could be related, adopted, and applied.

Sceptics of active learning say that a well-executed traditional lecture class will be more effective than a poorly-executed active learning class, thus highlighting the ability, skill and experience required to be a good active learning facilitator. In my case, I was at a transition point, where I started experiencing the benefits of my initial (and no doubt inexperienced) attempts at preparing for active learning classes. I reflected on much of my decade-long traditional teaching experience and more than a decadelong learning experience as a student myself in a traditional classroom setting and started to re-focus on the new mode of delivery. There is a time period for the instructor's and the students' expectations to be aligned properly for the class to be more successful. Within three years since coming to the university, I had changed from a diligent, meticulously-prepared, well-versed classroom lecturer with good examples and attention-grabbing visual aids that pop up at the right moment during the lecture flow, into a more responsive, on-the-spot-discussion instructor who adaptively sources his materials and examples for each class from the students' interests and projects. Within three years since enrolling in the university, the students have been transformed from passive-thinking, quiet and conforming students who wait for the teacher to spoon-feed them with ready-made, packaged knowledge, into pro-active, critical-thinking, self-initiated students who try without fear of losing face or making mistakes in front of their peers and instructors. I do not think that I would ever prepare any more courses with a generic introduction of concepts and a general explanation of topics in the future, at least not for the students in this university.

It is said that an average college student has an attention span of 10-20 minutes (Souas, 2000; Thomas, 1972), but this is when the class is run in a traditional lecture mode. Typical problems in a conventional classroom situation, such as difficulty in maintaining the students' attention and keeping them engaged, giving a clear explanation of a complex concept, or students doing other things or chatting with other students, etc., do not even become an issue when everything starts with the students' own interests (progress of their own project in order to get good grades) and stays that way.

\subsection{From teaching to advising to observing}

Even though my students were new to the topic of the course (i.e. Human-Computer Interaction and Interaction Design), my role as the instructor shifted from "teaching" them to "advising" them to eventually "observing" them. This is related to the previous point on how the course was no longer a general introduction of new topics and concepts but a specific guidance of the students' own projects through which they learn the topics and new concepts. The students were vocal, curious and solely focused on the progress of their own projects throughout the course (no doubt motivated by the desire to earn good grades). Thus, the role of advising them on the specifics of their own projects seamlessly matched their mind-set and attitude. I am quite certain that it is necessary for the instructor to have the ability to quickly catch the gist of the progress status of each project and to discern in what way the advice should be given. Week by week, my approach was 
increasingly changing from teaching students to advising them in this way. This was my personal experience, but perhaps it underlines the well-known active learning phrase, "from sage on the stage to guide on the side" (King, 1993). If our students' expectation had been that of a traditional cohort familiar with a passive, lecture-style classroom, then I as an instructor might have been considered to be an ill-prepared teacher with no clear agenda for teaching who only liked to chat with the students. After three years of active learning classes, our students enjoyed and benefited from the individual, project-specific interaction and discussion sessions with me, again highlighting the good match and timing between my own progress as an active learning facilitator and the students' progress as active self-learners.

I had the scheduled teaching components of the new concepts, but these had also been shifted into small bits of mini-lectures and illustrations of examples. I started preparing these by constantly thinking of breaking the concepts into action-oriented activities or discussion points, where each team could relate the example snippets to the context of their own projects. Two of the largest and most concerted activities in the course were the mid-term and end-term presentations by each team. The presentations summarised their exploration of design options, decisions made and the interaction strategies they came up with. Even though these presentations had relatively small grading weights (together they comprised 20\% of the full course mark), it was noticeable that the teams scheduled their projects based on these two milestones in order to push their understanding of the problems, with team members arguing and agreeing with each other, and perhaps most importantly, teaching and explaining amongst themselves. Peer-to-peer learning was already familiar to my students and they were already aware that one of the best ways to learn is to teach or explain (Sousa, 2000). When students learn from each other, and the intensity of such learning is maintained throughout the course, they benefit from a reduced anxiety level of competition and enhanced efficiency in learning (Giordano \& Hammer, 1999), but the instructor benefits also as there is less work to do. This came as a welcome surprise to me as the team members went full speed ahead with their projects. When this shift from teaching to advising to eventually just being hands-off and observing came through in this course, I had no doubts that this was the active learning moving in the right direction.

\subsection{From preparation to on-the-spot collision}

It became obvious as the weeks went by in the semester that my energy and resources were better spent during the class hours rather than during the pre-class preparation. There were still various mini-lectures and example snippets that I had to prepare to make the class run more optimally and smoothly. However, the core of the learning and the essence of the course that my students most benefited from, were the studio-style, within-project discussions that took up $70 \%$ of the class hours. Thus, I started putting even less effort into the general preparation for the classes but far more efforts into in-class discussions with the student teams. It is necessary for the instructor to just participate in the discussion sessions and to address whatever imminent topics may be discussed by the team at that point in time. Again, I realise that this is an aspect that requires the instructor's experience to quickly catch the project-specific design issues and the ability to quickly relate them to the general knowledge in order to assemble and advise accordingly on the spot during that discussion time.

One of the changes in my view of the course and my attitude towards the teaching was this shift of my attention from a careful and well-thought-out preparation of the course materials to the vigour and energy that I was prepared to expend during the team discussion time in the class. At times I felt insecure and ill-prepared, not knowing exactly where the discussions would lead to. The control rested collaboratively on me and the team members, and was not solely on me.

One of the main reasons why teachers in college and university settings are sceptical about active learning delivery is the perceived time and effort that they are required to put into their preparation (TokuhamaEspinosa, 2007). This was the initial concern for me and also for many of my colleagues, who were just starting at the university. After three years of being actively involved in developing and delivering these courses, I have come to realise, more and more, that the actual preparation time is considerably less than that which is needed for a typical lecture class. The most valuable attribute of active learning in my course was how I interacted with the student teams and individual students in dealing with their specific problems, questions and issues, and in facilitating the on-the-fly interaction that benefitted them at each moment. Any resources that I had at my disposal-all my past experiences, knowledge both tacit and coded, 
practical know-how, views on designs, example cases that I knew or had been involved in, etc. - were on call at any moment, to be used in such on-the-fly and spontaneous interaction sessions. The eventual development and success of this course depended on the instructor having such a capability. I consider this to be good news: from now on, I leverage on my know-how and knowledge-in-action and let it all happen on the spot, rather than make any lengthy preparations beforehand. After all, the students should benefit from the first-hand expertise of the instructor during the class.

\section{Conclusion}

Preparing and running the autumn course changed, in a significant way, my view of teaching and consequently, how I designed and conducted the course. This happened partly because the new university in which the course was conducted had a particular pedagogical stance with regard to teaching. The whole curriculum was to be in the form of active learning to instil design thinking, exemplified by trial-and-error and gain-knowledge-through-iteration attitudes. This pushed the submissive and passive students, who had been trained in a typical Asian primary and secondary education system, into quite an impressively pro-active, self-initiated, authority-challenging and argumentative gang of young people, who are unafraid of making mistakes in front of their classmates, are extremely articulate in expressing their ideas and are very familiar with teamwork situations.

Three years after the university started its very first semester with the pioneer batch of students, there were two parallel streams of changes happening between the two interacting parties, namely, my students and me. The changes in the students were remarkable considering their baggage of conventional primary and secondary education that they initially carried over into the university. They had a strong theoretical knowledge base, albeit very passive, to use as their stepping stone to this shift in learning attitudes; and they had three years of training (roughly equivalent to 20 courses) in the new way of learning. The changes in me, as shared in this article, are perhaps less remarkable considering the fact that the most of these changes seem to confirm what has been pointed out in the literature advocating active learning. But I was fortunate to have this opportunity to be in the university to witness this fast-changing batch of students, who pushed me to re-think, revise and re-model my 10-year teaching experience to suit the characteristics of their cohort. While doing so, I had an experience of shifting of my own concepts on what constitutes teaching. Transforming an instructor's past teaching habits this much probably requires such an institutional push as I had, but from now on, in whatever teaching context I may find myself in, I know how I would do it differently.

Acknowledgement: Hans Anderson, a PhD student at SUTD who was also my teaching Assistant for this course, helped me during the studio session discussions with the teams. His knowledge and experience of working in the field of technology and software applications were great assets to the course and contributed to my reflections of the course.

\section{References}

[1] Calabro, K. M., Kiger, K. T., Lawson, and W, Zhang. G. (2008). New directions in freshman Engineering Design at the University of Maryland. ASEE/IEEE Frontiers in Education Conference, pp. T2D: 6-11

[2] Cross, N. (2007). Designerly ways of knowing. Basel: Birkhauser

[3] Freeman, S., Eddy, S., McDonough, M., Smith, M., Okoroafor, N., Jordt, H. and Wenderoth, M. (2014). Active learning increases student performance in science, engineering, and mathematics. Proceedings of the National Academy of Sciences of the United States of America, 111 (23)

[4] Giordano, P.J., and Hammer, E.Y. (1999). In-class collaborative learning: practical suggestions from the teaching trenches. Teaching Psychology, 26(1), 42-44

[5] Goh, K., Goodman, P., \& Weingart, L. (2013). Team innovation processes: an examination of activity cycles in creative project teams. Small Group Research, 44, 159-194

[6] King, A. (1993). From sage on the stage to guide on the side. College Teaching, 41(1), 30

[7] Lawson, B. (2005). How designers think (4th Ed.). London, U.K.: Routledge

[8] Lee H, Mohamad Ali N and Hardman L. (2013). Designing interactive applications to support novel activities. Advances in Human-Computer Interaction. Vol. 2013, ISSN: 1687-5893

[9] Lee $\mathrm{H}$ and Smeaton A.F. (2009). Interaction platform-orientated perspective in designing novel applications. Create 2009Creative Inventions and Innovations for Everyday $\mathrm{HCl}$, London, U.K., 1-2 July 2009

[10] Linsey, J., Talley, A., White, C. K., Jensen, D., and Wood, K. L. (2009). From tootsie rolls to broken bones: an innovative approach for active learning in mechanics of materials. ASEE Journal of Advances in Engineering Education (AEE), 1(3), 1-23

[11] Stewart, V. (2012). Transforming learning in cities: the global cities education network inaugural symposium. Asia Society Partnership for Global Learning. Hong Kong, May 10-12, 2012.

[12] Souas, D. (2000). How the brain learns. Thousand Oaks, CA: Corwin Press 
[13] Telenko, C., Camburn, B., Holtta-Otto, K., Wood, K., and Otto, K. (2014). Designettes: new approaches to multidisciplinary engineering design education. ASME International Design Engineering Technical Conferences and Computers and Information in Engineering Conference, Buffalo, NY, U.S.A., 17-20 August, 2014

[14] Thomas, J. (1972). The variation of memory with time for information appearing during a lecture. Studies in Adult Education, 4, 57-62

[15] Tokuhama-Espinosa, T. (2007). Active learning in practice at the university level. Tracey Tokuhama-Espinosa (http://traceytokuhama.com/). Available online at: http://traceytokuhama. com/publications/papers-unpublished/active-learning-inpractice-at-the-university-level/261
[16] Tsai F, Natarajan K, Ahipasaoglu S, Chau Y, Lee H, Cheung N, Ruths J, Huang S and Magnanti T. (2013). From boxes to bees: active learning in freshmen calculus. The 4th Annual IEEE Global Engineering Education Conference (EDUCON 2013), Berlin, Germany, 13-15 March 2013

[17] Wood, K., Mohan, R., Kaijima, S., Dritsas, S., Frey, D., White, C., Jensen, D., Crawford, R., Moreno, D., and Pey, K. (2012). A symphony of designettes exploring the boundaries of design thinking in engineering education. 119th ASEE Annual Conference and Exposition, San Antonio, TX, U.S.A., 10 -13 June, 2012 